\begin{tabular}{|c|c|}
\hline Proceeding of the $9^{\text {th }}$ ICEE Conference 3-5 April 2018 & NBC \\
Military Technical College \\
Kobry El-Kobbah, \\
Cairo, Egypt
\end{tabular}

NBC-3

\title{
Studying the Biochemical and Biophysical Properties of Edible Oils after Normal and Microwave Heating and Reheating
}

\author{
Khedr Y I ${ }^{1}$, Kotb MA ${ }^{2}$, Ramadan $\mathrm{HS}^{2}$, Nasra $\mathrm{MK}^{2}$, Siam ME ${ }^{3}$, El-Khatib AM ${ }^{4}$
}

\begin{abstract}
The present study was undertaken to investigate the effect of heating, reheating and exposure to microwave radiation on some biophysical and biochemical properties of edible oils. In homes and restaurants, vegetable oils used for cooking are usually heated to very high temperatures, and may be reused several times to save costs. The recycling process involves repetitive heating of the oils may be bad for health. In this study used four samples of edible oils such as olive oil, cotton seeds oil, supply oil and corn oils in which used two kilograms for each sample and were collected from the origin of production in the local market and considered as fresh oils. The biophysical results showed that viscosity, refractive index of edible oils increase with the increase of heating frequency, this increase is higher in case of normal heating than microwave heating, the color intensity increased with normal heating and decreased with microwave exposure. The biochemical results revealed that the saponification number, the acid and peroxide values increased with increasing frequency of heating by both methods and the iodine number decrease by increased heating by the two methods. From this results it is concluded that the normal heating for four times induced biophysical and biochemical changes that must be taken in consideration, using microwave exposure induces minor changes in biophysical and biochemical properties and the olive oil showed the lowest level of changes which may be due to its high content of monounsaturated fatty acids, which may be the reason of its least autoxidation of rancidity
\end{abstract}

\section{Keywords:}

Edible oils, microwave, viscosity, refractive index, iodine number, peroxides.

1 Dept. of physics, Faculty of Science, Damanhur University, Egypt.

2 Dept. of Medical- Biophysics, Medical Research Institute, Alexandria University.

3 Ministry of Industry, Egypt.

4 Dept. of Physics, Faculty of Science, Alexandria University. 
Military Technical College

Kobry El-Kobbah, Cairo, Egypt

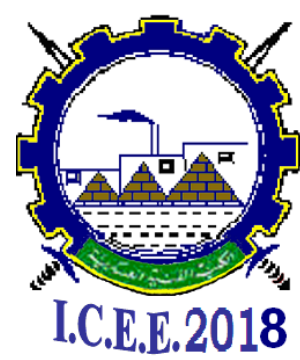

$9^{\text {th }}$ International Conference

on

Chemical \& Environmental

Engineering

3-5 April 2018

\section{Introduction}

Edible oils from either plant or animal sources are of special interest in various food and industrial applications. In general edible oils provide characteristic flavors and textures to foods as integral diet components [1] and can also serve as a source of oleo chemicals which are completely biodegradable and so could replace a number of petrochemicals [2].

Vegetable oils play important functional and sensory roles in food products, and they act as carriers of fat-soluble vitamins (A, D, E, and K). They also provide energy and the essential fatty acids (linoleic and linolenic acids), responsible for growth [3]. One important parameter of different vegetable oils is the amount of unsaturation of the constituent fatty acids [4,5] Fatty acids, esterified to glycerol, are the main constituents of oils and fats. The industrial exploitation of oils and fats, both for food and oleochemical products, is based on chemical modification of both the carboxyl and unsaturated groups present in fatty acids. Although the most reactive sites in fatty acids are the carboxyl group and double bonds, methylenes adjacent to them are activated, increasing their reactivity. Only rarely do saturated chains show reactivity. Carboxyl groups and unsaturated centers usually react independently, but when in close proximity, both may react through neighboring group participation. In enzymatic reactions, the reactivity of the carboxyl group can be influenced by the presence of a nearby double bond [6].

In homes and restaurants, vegetable oils used for cooking are usually heated to very high temperatures, and may be reused several times to save costs. The recycling process involves repetitive heating of the oils. Successive heating of oils several times may be bad for health. Heated vegetable oils were found to have higher content of free radicals compared to fresh oils that used for first time. Reactive oxygen species present in the heated oils can impair bone metabolism due to lipid peroxidation if taken as part of the daily diet.

Over the last few decades, the microwave heating process has experienced more common and routine use for both home and industrial applications. In industrial field, microwave heating has been used for many applications, including food processing and preservation, bleaching, pasteurization, and sterilization. Microwave heating of roasted seeds and beans shows a better retention of flavor and antioxidant compounds without any significant chemical changes of the lipids [7]. With respect to lipid components, microwave heating was studied to verify eventual heat induced effects on different oils and fats [8] for this purpose, peroxide value, carbonyl value and conjugated diene and triene levels were assessed.

Different works have been aimed to evaluate the effects of microwave heating on food and it constituents, including in lipid fraction of animal fats and vegetable oils, The microwave heating process could accelerate oxidative reactions which promote the involvement of free radicals [9].Several other factors could also interfere in lipid oxidation processes, such as, fatty acid composition, free fatty acids, oxygen exposure, 
Military Technical College

Kobry El-Kobbah, Cairo, Egypt

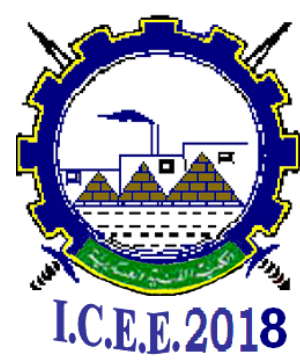

$9^{\text {th }}$ International Conference

on

Chemical \& Environmental

Engineering

3-5 April 2018

heat, water[10], physic state, light, trace metals, antioxidants [11], between others. Being the temperature the most important.

The most important cause of oil and fat deterioration is the oxidation process which not only reduces both shelf life and the nutritional value of these products but also produces toxic compounds. The application of fast, reliable and low environmental impact analytical methods for monitoring the thermal stability of vegetable oils and the oxidation degree resulting from time-temperature combination of heating treatments (microwave exposure), are nowadays requested.

\section{Materials and Methods}

\subsection{Edible Oil Samples}

In the present work samples of edible oils; olive oil, cottonseeds oil, sunflower oil, supply oil (sunflower $75 \%$ and soybean oil $25 \%$ ) and corn oil were used, to integrate the effect of temperature on some of their physical and chemical properties. The mass of the sample from each type was $2 \mathrm{Kg}$. The oils were collected from the origin of production in the local market and considered as fresh oils. Each sample was divided into three main parts as follows: the first part was used as control part (corresponding to zero min). Afterwards, the samples were kept in Falcon tubes and refrigerated until analysis for determining the biophysical and biochemical properties before heating, re-heating or microwave exposure. The second part was used to study the effect of normal heating on the physical and chemical properties of the considered oils. This part was divided into three sub-parts for studying the effect of normal heating (N-heating) in all studied oil samples were subjected to heating using flame oven, reheating (once and more). Each heating period was $20 \mathrm{~min} /$ day for 4 days. Heating and reheating once and /or more were considered to resemble the conditions in daily life as can as possible. The third part was used to study the effects of exposure of edible oils to microwave radiation on some biophysical and biochemical properties of edible oils i.e flash temperature, viscosity, refractive index, color intensity, saponification number, iodine number, acid value peroxide value.

\subsection{Microwave Oven (MW)}

Five hundred $\mathrm{ml}(500 \mathrm{~mL})$ of each oil was individually placed in a Petri dish $(15 \mathrm{~cm}$ in height and $22 \mathrm{~cm}$ in diameter) and subjected to heating in a microwave oven at maximum potency ( $800 \mathrm{Watt}$ ) for $20 \mathrm{~min} /$ day for 4 days. The exposed samples were kept in Falcon tubes and refrigerated until analysis [12] the microwave oven used was Sharp model R241R(S), serial No: 10075380 with $800 \mathrm{~W}$ effective power and $2450 \mathrm{MHz}$ frequency.

\subsection{Determination of Biochemical Properties}

\subsubsection{Effect of Normal and Microwave Heating on some Chemical Properties of Edible Oil}


Military Technical College

Kobry El-Kobbah, Cairo, Egypt

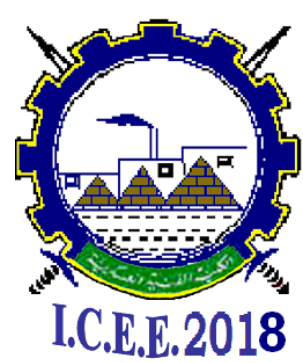

$9^{\text {th }}$ International Conference

on

Chemical \& Environmental

Engineering

3-5 April 2018

\subsubsection{Saponification Number $(\mathrm{SN})$}

Two $\mathrm{g}$ of oil was weighed accurately and put into a conical flask containing $25 \mathrm{ml}$ of 0.5 $\mathrm{M}$ alcoholic $\mathrm{KOH}$. Reflux condenser was fitted to the flask containing the ionic solution and heated in a water bath for an hour swirling the flask frequently. Excess $\mathrm{KOH}$ was titrated hot with $0.5 \mathrm{M}$ HCI using $1 \mathrm{ml}$ of phenolphthalein (1\%) solution. The saponification value was calculated from the difference between the blank and the sample titration, the saponification number can be determined from the following formula [13].

$$
\text { Saponification Number }=\frac{(b-a) \times 28.05}{W t(\text { in } g) \text { of sample }}
$$

Where $b=$ titration value of blank; $a=$ titration value of sample; $28.05=\mathrm{mg}$ of $\mathrm{KOH}$ equivalent to $1 \mathrm{~mL}$ of $0.5 \mathrm{M} \mathrm{HCI}$.

\subsubsection{Iodine Number (IN)}

Different samples of oils (corn oil, sunflower oil, olive oil, cotton oil and supply oil (tamween oil)) was added and suitably weighed in a dry glass-stoppered bottle. The appropriate weight in gram of the olive oil to be used was calculated by dividing 20 by the highest expected iodine value, the stopper was inserted (previously moistened with potassium iodide solution) and allowed to stand in the dark for 30min. Of potassium iodide (10\%) $15 \mathrm{ml}$ was added and mixed with $100 \mathrm{ml}$ water. The solution was titrated with $0.1 \mathrm{ml}$ thiosulphate solution using starch indicator just before the endpoint (titration $=\mathrm{a} \mathrm{ml}$ ). Blank was treated at the same time commencing with $100 \mathrm{ml}$ of carbon tetrachloride (titration $=\mathrm{b} \mathrm{ml}$ ), the iodine value was determined by Wijs' method the iodine number can be determined according to the following formula [13].

$$
I N=\frac{N \text { of } I_{2} X(b-a) X 1000 X 100}{W t . \text { of oil }(g) X 127}
$$

\subsubsection{Peroxide Value (PV)}

One $\mathrm{g}$ of oil samples was weighed and poured into a dry $250 \mathrm{ml}$ stoppered conical flask. Ten $\mathrm{ml}$ of chloroform was added and the oil was dissolved by swirling. $15 \mathrm{ml}$ of glacial acetic acid and $1 \mathrm{ml}$ of fresh saturated aqueous potassium iodide solution were added. The flask was stoppered, shaken for $1 \mathrm{~min}$ and placed for $1 \mathrm{~min}$ in the dark. Thereafter $75 \mathrm{ml}$ of water was added, mixed and the freed iodine was titrated with $0.002 \mathrm{M}$ sodium thiosulphate solution using soluble starch solution $(1 \%)$ as an indicator. The titration value was recorded as $\mathrm{V}$. Blank determination $\left(\mathrm{V}_{\mathrm{o}}\right)$, the peroxide value was determined according to the following formula [13]. 


\begin{tabular}{|l|c|}
\hline Proceeding of the $9^{\text {th }}$ ICEE Conference 3-5 April 2018 & NBC \\
Military Technical College \\
Kobry El-Kobbah, \\
Cairo, Egypt
\end{tabular}

$$
P V=\frac{\left(V-V_{0}\right) T}{M} \times 10^{3} \mathrm{mEq} / \mathrm{Kg}
$$

Where $\mathrm{T}=$ exact molarity of sodium thiosulphate solution.

\subsubsection{Acid Value (AV)}

$25 \mathrm{ml}$ diethlyether were mixed with $25 \mathrm{ml}$ ethanol, add $1 \mathrm{ml}$ phenol. Phenol solution (1\%) and carefully neutralize with $0.1 \mathrm{M}$ of $\mathrm{NaOH}$. Dissolve $1 \mathrm{~g}$ of oil or fat in the mixed neutral solvent and titrate with $0.1 \mathrm{M} \mathrm{NaOH}$ soulution. Shaking constantly until a pink color persists for $15 \mathrm{sec}$ is obtained the acid value was determined according to the following formula [13].

$$
\text { Acid value }=\frac{\text { Titration } m l \times 5.61}{\text { wt of sample }(\text { in } g m)}
$$

\subsection{Determination of Biophysical Properties}

\subsubsection{Oil Color}

Oil color was measured using photoelectric colorimeter model "vini lab", unheated oil (control) is used as a blank to adjust zero color at $530 \mathrm{~nm}$. Reading a sample is considered against to unheated oil.

\subsubsection{Refractive Index}

The instrument used to measure the refractive index is called a refractometer. Following the standard method, introduce the sample to be measured between the two prisms. If it is a free-flowing liquid, it may be introduced into a channel along the side of the prisms, injected from a Pasteur pipet. If it is a viscous sample, the prisms must be opened (they are hinged) by lifting the upper one; a few drops of liquid are applied to the lower prism with a Pasteur pipet or a wooden applicator. If a Pasteur pipet is used, take care not to touch the prisms because they become scratched easily. When the prisms are closed, the liquid should spread evenly to make a thin film. With highly volatile samples, the remaining operations must be performed rapidly. Even when the prisms are closed, evaporation of volatile liquids can readily.

\subsubsection{Viscosity}

Viscosity was measured using Brookfield Viscometer Model DV-II, mad in Germany. 
Military Technical College Kobry El-Kobbah, Cairo, Egypt

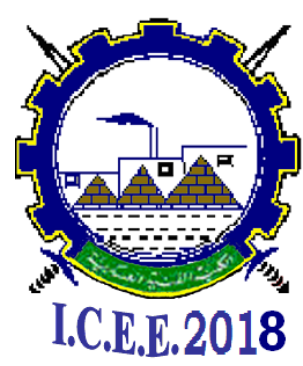

$9^{\text {th }}$ International Conference

on

Chemical \& Environmental

Engineering

3-5 April 2018

\section{Results}

\subsection{Effect of Normal and Microwave Heating on some Physical Properties of Edible Oils.}

\subsubsection{Color Intensity}

The intensity of color of the studied oils showed significant increase with the exposure time in case of normal heating. For microwave exposure, there was decrease in color with increasing exposure time as shown in Fig.1, 2 which illustrates the color intensity and percentage changes of edible oils after heating four times, using normal heating and microwave exposure respectively.

\subsubsection{Refractive index}

The effect of normal heating on refractive index for all studied oils showed that refractive index increases for normal and microwave heating with increasing exposure time but with lower level for microwave heating than that resulted from normal heating, Table.1\&2 Illustrates the refractive index and percentage changes of edible oils after heating four times, using normal heating and microwave exposure

\subsubsection{Viscosity}

The effect of normal heating on viscosity of all studied oils showed that by increasing time exposure for normal heating, the viscosity increase. While microwave heating showed increased viscosity with increasing exposure time but this increase was significantly less than that resulted from normal heating, Fig. $3 \& 4$. The percentage changes in viscosity of edible oils after heating four times, using normal heating and microwave exposure, its exhibit increased in viscosity percentage for both cases as revealed in Table3.

\subsubsection{Flash Temperature}

For all studied oils used the flash temperature were decreased by increasing time exposed for normal heating. Table.4\&5 revealed the flash temperature of edible oils after heating four times, using normal heating respectively.

\subsubsection{Saponification Number}

Intense heating for oils using normal heating for 25 min repeated four times resulted in significant increase in saponification number with increasing exposure time. Microwave exposure $20 \mathrm{~min}$ repeated four times showed decreased saponification number compared with normal heating at corresponding time intervals, Increasing exposure time for microwave heating did not increase saponification significantly, Fig(5\&6).Table(6) revealed the saponification number and percentage changes of edible oils after heating four times, using normal and microwave heating. 
Military Technical College

Kobry El-Kobbah, Cairo, Egypt

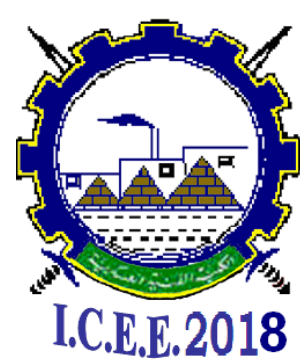

$9^{\text {th }}$ International Conference

on

Chemical \& Environmental

Engineering

3-5 April 2018

\subsubsection{Acid value}

Intense heating for oils using normal heating for 25 min repeated four times resulted in significant increase in acid number with increasing exposure time. While microwave exposure $20 \mathrm{~min}$ repeated four times showed significant decreased values for acid number compared with normal heating at corresponding time intervals, but increasing exposure time for microwave heating did not increase acid number significantly, Fig.7 the lowest acid number was for olive oil and corn oil after 100 min exposure for normal heating $(19.074,22.44)$ respectively, while the highest acid number was for supply oil, sunflower oil $(41.514,39.27)$ respectively.

\subsubsection{Iodine Number}

For Iodine number, normal heating resulted in significant decrease in iodine number with increasing exposure time which was significant compared with that after microwave heating, and the increasing exposure time for microwave heating did not affect iodine number significantly. As shown in Fig.9. The lowest iodine number was for supply oil and sunflower oil after $100 \mathrm{~min}$ exposure for normal heating $(17.78,19.05)$ respectively, while the highest iodine number was for olive oil and corn oil $(67.945,41.91)$ respectively.

\subsubsection{Peroxide value}

For Peroxide value, normal heating resulted in significant decrease in Peroxide value with increasing exposure time which was significant compared with that after microwave heating. Increasing exposure time for microwave heating did not affect Peroxide value significantly. Fig.11. illustrate that the lowest Peroxide value was for olive oil and corn oil after $100 \mathrm{~min}$ exposure for normal heating $(12.296$, 13.4) respectively, while the highest Peroxide value was for sunflower oil and supply oil $(25.864,25.652)$ respectively.

\section{Discussion}

Edible oils from plant sources are of interest in various food and application industries. They provide characteristic flavours and textures to foods as integral diet components [1] and can also serve as a source of oleo chemicals [14]. Oleo chemicals are completely biodegradable and so could replace a number of petrochemicals [2].Vegetable oils play important functional and sensory roles in food products, and they act as carrier of fat soluble vitamins A, D, E, and K [15].They also provide energy and essential linoleic and linolenic acids responsible for growth [16]. Vegetable oils are mostly used for cooking and frying of foods and snacks. In both applications, the oils are subjected to elevated temperatures in the range of 35 to $180^{\circ} \mathrm{C}$.The optimum design of heating and cooling systems for cooking and frying, and the fundamental understanding of cooking and 
Military Technical College

Kobry El-Kobbah, Cairo, Egypt

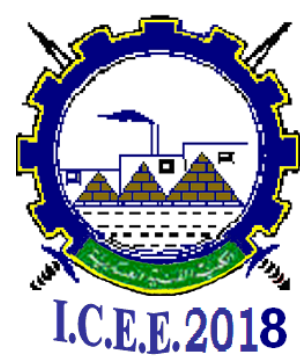

$9^{\text {th }}$ International Conference

on

Chemical \& Environmental

Engineering

3-5 April 2018

frying processes require that the thermo-physical properties of the major ingredients involved such as vegetable oil in these processes to be known[17].

Changes of fats and oils have been studied as the temperature of fat and oils can substantially increase during the operation, the temperature of the fat phase increases twice as fast during the microwave heating than the temperature of water or water containing foods under comparable conditions.

Microwave process can offer several distinct advantages when compared to conventional methods. These advantages include speed of operation, energy savings, precise process control, and faster start up and shut-down times [18]. Heating of food in a microwave oven is caused by interaction of an electromagnetic field with the chemical constituents of food. These interactions comprising molecular friction and excitation generate heat necessary for cooking purposes $[18,19]$.The effect of microwave heating on animal and vegetable fats have been investigated [20] as have its influences on thermo-oxidative stability of common oils and fats in house-hold use. Little has been published on the changes in composition and oxidative stability of the oils during microwave oven heating [21].

Few studies, however, have been published concerning the comparison of the effects of microwave heating with those of conventional heating systems. Further studies would thus be necessary to clearly define the differences, if any, between the effects induced by conventional and by microwave heating on edible oils [22].

To test the hypothesis that there would be differing effects between normal heating and microwave heating, different edible vegetable oils (olive oil, sunflower oil, cotton oil, corn oil and mixed oil ) were heated either by normal heating or in a microwave oven and the variations induced by the two different thermal treatments on the chemical properties including (saponification value, acid number, iodine number and peroxide value) in addition to the physical properties including ( refractive index, viscosity, color intensity) were assessed. Some authors have studied the degradation process of edible oils submitted to high temperatures with aeration. In these studies, The peroxide value, the acid value, free fatty acid concentration, or gain of oxygen, and the evolution of several acyl groups of polar compounds of oligomeric and polymeric degradation products, were determined [23-26].

In general, the results obtained in these studies showed that oils with a higher content in polyunsaturated groups are less resistant to oxidation [27, 28] than oils with a low content in polyunsaturated acyl groups, although the influence of minor components on oil stability has also been shown [25].

In daily life cooking activity with edible oils, it is very important to know some ideas about both the smoke point and the flash point of the edible oils used. The smoke point of an oil or fat is the temperature at which it begins to break down to glycerol and free fatty acids, and produce bluish smoke. The glycerol is then further broken down to acrolein which is a component of the smoke[29]. It is the presence of the acrolein that causes the smoke to be extremely irritating to the eyes and throat. The smoke point also marks the beginning of both flavor and nutritional degradation. Therefore, it is a key 
Military Technical College

Kobry El-Kobbah, Cairo, Egypt

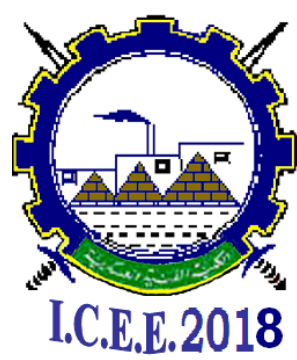

$9^{\text {th }}$ International Conference

on

Chemical \& Environmental

Engineering

3-5 April 2018

consideration when selecting a fat for frying, with the smoke point of the specific oil dictating its maximum usable temperature and therefore its possible applications. For instance, since deep frying is a very high temperature process, it requires a fat with a high smoke point.

The smoke point for an oil varies widely depending on origin and refinement [30] The smoke point of an oil does tend to increase as free fatty acid content decreases and degree of refinement increases [31]. Heating oil produces free fatty acid and as heating time increases, more free fatty acids are produced, thereby decreasing smoke point. It is one reason not to use the same oil to deep fry more than twice [30].

Considerably above the temperature of the smoke point is the flash point, or the flash temperature. It is the point at which the vapors from the oil can first ignite when mixed with air. So, both smoke point and flash point are inter-correlated, i.e., as the smoke point increases or decreases, the flash point increases or decreases. In this work, the results indicated decreased level of the flash point of the used edible oils. The percentage of changes was in the order: supply oil $(20.6 \%)<$ olive oil $(22.5 \%)<$ cotton oil $(30.8 \%)$ $<$ corn oil $(35.5 \%)<$ sunflower oil $(35.7 \%)$. This means that the liberation of more fatty acids as a result of repetitive normal heating. This gives us a conclusion concerning the use of edible oils in cooking. As the flash point decreases, it is advisable to use edible oils once or twice on the maximum.

The procedure of normal heating and microwave heating simulated the process of deep frying. During $20 \mathrm{~min}$ of microwave heating, most often used for food frying in a microwave oven, the temperature of oils increased to nearly $200^{\circ} \mathrm{C}$, and further increase was only negligible. The temperature of oil rises at a substantially higher rate than in the case of water, due to its lower permittivity and specific heat [32], The course of temperature changes was nearly the same in all cases.

According to the food industry, viscosity is one of the most important parameters required in the design of technological process. Viscosity is also an important factor that determines the overall quality and stability of a food system. Therefore, viscosity must be closely correlated with the structural parameters of the fluid particles. On the basis of published data concerning flow properties of oils, the oil viscosity has a direct relationship with some chemical characteristics of the lipids, such as the degree of unsaturation and the chain length of the fatty acids that constitute the triacylglycerols. The viscosity slightly decreases with increased degree of unsaturation and rapidly increases with polymerisation. The results of the present work concerning the viscosity of the oils showed that in both normal and microwave heating, there was an increase in the viscosiy as a result of repeating heating. The results of the percentage of changes with the type of oil was in the order: Olive oil $(27.5 \%)<$ corn oil $(53.8 \%)<$ sunflower $(53.2 \%)<$ supply oil $(67 \%)<$ cotton oil $(61 \%)$. These results are in line with that reported by Susheelamma et al who studied the physical properties of six commonly used oils after three successive frying by normal heating. Their results showed that viscosity and color of the oils changed to a much higher extent after first firing than subsequent frying. That could be indicated an increase in the formation of conjugated 
Military Technical College

Kobry El-Kobbah, Cairo, Egypt

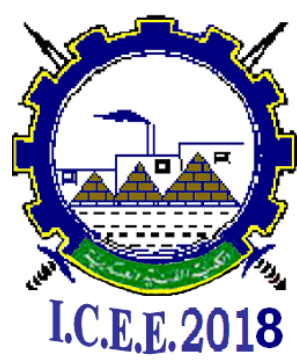

$9^{\text {th }}$ International Conference

on

Chemical \& Environmental

Engineering

3-5 April 2018

compounds after successive frying [33].It has been well established that temperature has a strong influence on the viscosity of fluid products with viscosity generally decreasing with increase in temperature [34] Several researchers have reported the viscosity of vegetable oils at room temperature[34]. Studies have also been carried out on the effect of temperature on the viscosity of some vegetable oils at temperatures less than $110^{\circ} \mathrm{C}[35]$ and at temperatures between $150-180^{\circ} \mathrm{C}$ [36]. The authors did not find any reported study on the viscosity of vegetable oils at temperatures between $110-150^{\circ} \mathrm{C}$. Moreover, these studies that have been carried out on temperature effect on viscosity of vegetable oils have been carried out at different temperature ranges. The results of this work revealed that by increasing temperature of vegetable oils, the viscosity increased using the two methods of heating carried out. However, the level of changes is much higher in case of normal heating than the case of using microwave exposure. This could be explained on the base that certain properties of fatty acid residues in the molecule of triacylglycerol have significant effects on the fluidity of the oil [30]. Most of the bonds in the hydrocarbon chains of fatty acids are single bonds. This linear " zig-zag " organisation enables the chains to be lined up close to each other and intermolecular interactions such as Van der Waals interactions can take place. This system inhibits flow of the fluid, resulting in the relatively high viscosity of the oils. The presence of double bonds, which in fatty acid residues exist in cis configurational form, produces "kinks" in the geometry of the molecules. This prevents the chains coming close together to form intermolecular contacts, resulting in an increased capability of the fluid to flow.

According to our results as temperature increases the degradation rate of double bond increase and the linear configuration of the oils become closer to each other leading to decreased oil fluidity resulting in increased viscosity. Our results are in agreement with that obtained by Hojjatoleslamy. They investigated the viscosity of vegetable oils as a function of the shear rate and also shear stress as a function of shear rate at temperatures ranging from 10 to $80^{\circ} \mathrm{C}$. As a result, the Sunflower oil and soybean oil (more linoleic) had more yield stress at $10^{\circ} \mathrm{C}$ than Canola oil (more oleic) at the same temperature. Also, during heating, oils containing higher unsaturated fatty acids (soybean oil and Canola oil) showed Newtonian behavior earlier than oils containing less unsaturated fatty acids (Sunflower oil). It means that a more rapid viscosity change with temperature was observed in the oils containing more double bonds due to their loosely-packed structure.

Photometric color values were determined as a measure of comparing the changes in the color of the five edible oils used in this work before and after heating with either normal heating or microwave exposure. The results revealed that with increasing frequency of normal frying the color index increases the order of increasing is: sunflower $(0.1-0.59)>$ supply oil $(0.1-0.27)>$ cotton oil $(0.01-0.2)>$ corn oil $(0.01-0.15)>$ olive oil (0.01-0.04). In case of microwave exposure, the color index increases after the first frying process and then decreased after words. With the other types of edible oils, the color index decreased with increasing the frying frequency with the olive oil suffered the minimum level of changes. 
Military Technical College

Kobry El-Kobbah, Cairo, Egypt

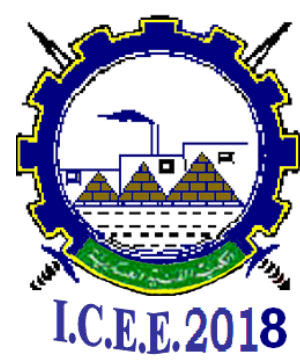

$9^{\text {th }}$ International Conference

on

Chemical \& Environmental

Engineering

3-5 April 2018

The effect of normal heating on refractive index for all types of edible oils considered showed that by increasing frequency of frying the refractive index increases. Similar behavior occurred with microwave exposure but with level low than that resulted from normal heating. The percentage of changes in case of normal heating was in the order: sunflower oil $(75.3 \%)>$ cotton oil $(68.5 \%)>$ corn oil $(41 \%)>$ olive oil $(34.1 \%)>$ supply oil $(21 \%)$. Since there is an inverse correlation between the refractive index and the density of the material, we can conclude that there is a variation of the density of the oils as a result of normal or microwave exposure. This conclusion needs further investigations to accept this conclusion.

The saponification number is a measure of the average molecular weight of the triacylglycerols in a sample. It is expressed as $\mathrm{mg} / \mathrm{g}$. From our study, it was found that the saponification number of all oils increases with time after both normal heating and microwave exposure. In case of normal heating, the increase in saponification number was in the order: olive oil $(173.9)<$ corn oil $(185.2)<$ cotton oil $(230)<$ sunflower oil (280.6) < supply oil (286.2). This order was also observed with the microwave exposure except that supply oil saponification number replaced that of the sunflower saponification number. This indicates that presence of greater number of ester bonds of intact fat molecules. This elevation of saponification number suggesting that oil may be used in production of liquid soap, shampoos, lather and shaving creams as reported by Ayoola \& Adeyeye. These results are in accordance with Pak who reported that high saponification value indicated the presence of greater number of ester bonds. Comparing the effect of microwave heating with normal heating showed that the saponification number of oils after microwave heating is much lower than that obtained after normal heating.

The acid value is defined as It is the number of milligrams of $\mathrm{KOH}$ required to neutralize the free fatty acids present in one gram of fat and it is used to describe the amount of free fatty acids present. and is expressed by $\mathrm{mgKOH} / \mathrm{g}$. Acid values of the studied oils after normal heating and microwave exposure were higher than that before heating. The increase in acid values with increasing frequency of normal frying was in the order: supply oil (41.5) > sunflower oil (39.3) > cotton oil (35.9) > corn oil (22.4) > olive oil (19). On the other hand, the variation in acid values in case of microwave exposure was in the order: sunflower oil $=$ supply oil $(16.8)>$ cotton oil $(13.5)>$ corn oil $(10.1)>$ olive oil (7.9).

According to Demian (1990) and Pak (2010), acid values are used to measure the extent to which glyceride in the oils has been decomposed by lipase and other actions such as light and heat. The determination is often used as the indication of the condition and edibility of oil. This indicates that the microwave exposure induces minor effects in acid values of the edible oils considered in this work [37].

The iodine number (IN) gives a measure of the average degree of unsaturation of a lipid: the higher the iodine value, the greater the number of $\mathrm{C}=\mathrm{C}$ double bonds. It is expressed by $\mathrm{mgI}_{2} / 100 \mathrm{~g}$. The iodine value reduced by increasing exposure time for normal heating and microwave heating which indicates low degree of unsaturation. In case of normal 
Military Technical College

Kobry El-Kobbah, Cairo, Egypt

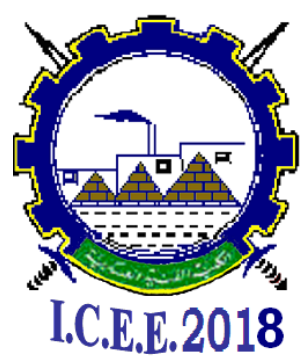

$9^{\text {th }}$ International Conference

on

Chemical \& Environmental

Engineering

3-5 April 2018

heating, the decreased level in iodine number was in the order: olive oil $(28.7 \%)<$ corn oil $(70)<$ cotton oil $(83.6 \%)<$ sunflower oil $(87.3 \%)<$ supply oil $(87.8 \%)$. The same order of percentage change was also observed in case of microwave exposure. The percentage of changes in the iodine number is lower in case of microwave exposure than that with normal heating.

Oxidative degradation of fats and oils during microwave heating depends on the polyenoic acid content and on the content of natural antioxidants. From the standpoint of unsaturated fatty acid composition, vegetable oils contained higher levels of linoleic acid (and a small amount of linolenic acid in the case of rapeseed oil), which increased their sensitivity against oxidative degradation [38].

The peroxide value is a measure of the content of hydro-peroxides, which are primary oxidation products. The changes of the peroxide value during normal heating and microwave heating showed that by increasing time or frequency of frying the peroxide value increase.

The order of changes in case of normal heating was: sunflower oil (25.9) > supply oil $(25.7)>$ cotton oil $(24.4)>$ corn oil $(13.4)>$ olive oil (12.3). The variation in the increased level of peroxide values with the microwave exposure was in the order: supply oil $(14.6)>$ sunflower oil $(12.9)>$ cotton oil $(12.5)>$ corn oil $(10.5)>$ olive oil (9.8).

The increase in peroxide values as a result of either heating with normal or microwave heating are coincide with that reported by Dostalova et al they studied the stability of Vegetable oils when heated in a microwave oven for up to 40 min between $25^{\circ} \mathrm{C}$ and $200^{\circ} \mathrm{C}$. They found that the peroxide value rose at high rate only after the end of the induction period, when the temperature reached about $150^{\circ} \mathrm{C}$. Therefore, the peroxide value continued to increase till the end of heating. The linoleic acid content is high in sunflower oil. This is the reason why the peroxide value started to increase rapidly. However, polyenoic hydro-peroxides are rather unstable at temperatures over $60^{\circ} \mathrm{C}$, the hydro-peroxide maximum is soon reached, and thus the peroxide value started to decrease again after prolonged heating because the rate of hydro-peroxide decomposition exceeded that of hydroperoxide formation. The same behavior was observed with rapeseed oil; only the peroxide maximum was lower than in sunflower oil because of a lower concentration of polyenoic fatty acids.

High-polyenoic acid oil used for food consumption - corn oil, showed a similar behavior on heating. Sekretar et al. determined the changes of the peroxide value during the microwave heating of lard, rapeseed, and sunflower oils. They obtained higher peroxide values, which can be explained by a lower temperature $\left(155^{\circ} \mathrm{C}\right)$ used in their experiments, in comparison with $180-200^{\circ} \mathrm{C}$ used in our experiments[39]. On the other hand low peroxide values could explain the negligible changes of essential fatty acids observed during the microwave heating. 
Military Technical College

Kobry El-Kobbah,

Cairo, Egypt

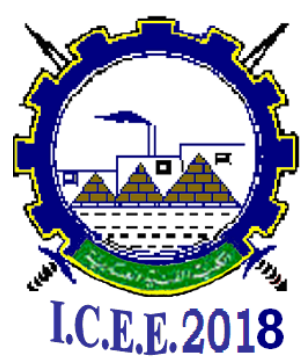

$9^{\text {th }}$ International Conference

on

Chemical \& Environmental

Engineering

3-5 April 2018

\section{Conclusion}

The results of this work can be summarized into the following:

1- The normal heating for four times induced biophysical and biochemical changes that must be taken into consideration.

2- Using microwave exposure induces minor changes in the biophysical and biochemical properties of the edible oils considered in this work, namely; Color intensity, refractive index, viscosity, flash temperature, saponification number, iodine number, acid value and peroxide value.

3- The olive oil showed the lowest level of changes, which may be due to its high content of monounsaturated fatty acids, which may be the reason of its least autooxidation and rancidity.

4- It is advisable to use microwave for heating oils or using normal heating once or twice times maximum.

\section{References}

[1] ODOEMELAM, S.A., Proximate composition and selected physicochemical properties of the seeds of African oil bean (Pentaclethra marcrophylla), Pak. J. Nutr., 2005, 4, 382-383.

[2] AYOOLA, P.B., A.A. ADEYEYE, Effect of heating on the chemical composition and chysico - chemical properties of Arachis hypogea (groundnut) seed flour and oil, Pak J. Nutr., 2010, 9(8), 751-754.

[3] Fasina O.O., Hallman C. H. M., and Clementsa C.(2006), Predicting TemperatureDependence Viscosity of Vegetable Oils from Fatty Acid Composition. JAOCS. 83(10): 899-903.

[4] Nikolas BK. ,Theophanis K.. Calculation of iodine value from measurements of fatty acid methyl esters of some oils; comparison with the relevant American oil. Chemists society method. JAOCS 2000; 77(12): 1235-1238.

[5] Sodamade A , Oyedepo TA , Bolaji O S. Fatty Acids Composition of Three Different Vegetable Oils (Soybean Oil, Groundnut Oil and Coconut Oil) by HighPerformance Liquid Chromatography. Chemistry and Materials Research 2013; 3(7): 26.

[6] Bilbao-Sainz C, Butler M, Weaver T, Bent J. Wheat starch gelatinisation under microwave irradiation and conduction heating. Carbohydrate Polymers 2007; 69:224-32.

[7] Behera, S., Nagarajan, S., \& Rao, L. J. M. Microwave heating and conventional roasting of cumin seeds (Cuminum eyminum L.) and effect on chemical composition of volatiles, Food Chemistry 2004; 87(1): 25-29. 
Military Technical College Kobry El-Kobbah, Cairo, Egypt

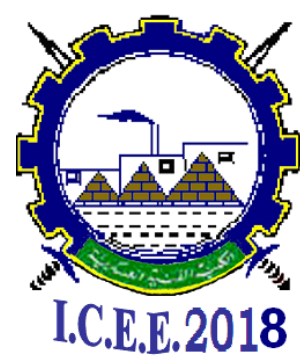

$9^{\text {th }}$ International Conference

on

Chemical \& Environmental

Engineering

3-5 April 2018

[8] Eckl PM. Genotoxicity of HNE. Molecular Aspects of Medicine 2003; 24(4):161165.

[9] Ricardo Malheiro, Ivo Oliveira, Miguel Vilas-Boas, Soraia Falco, Albino Bento, José Alberto Pereira., Effect of microwave heating with different exposure times on physical and chemical parameters of olive oil. Food and Chemical Toxicology. $2009 ; 47 ; 92-97$.

[10] Coulombe R, Gelin K. Spontaneous ignition of vegetable oils: Chemical composition. In: Proceedings of the Interpol Congress; 2002; Lyon, France, 2002.

[11] Frankel EN. Interfacial lipid oxidation and antioxidation. J. Oleo Sci. 2001; 50; 387-91.

[12] Moharam MA, Abbas LM. African Journal of Microbiology Research 2010; 4(19) ; 1921-7.

[13] Akinola F.F , Oguntibeju O.O , Adisa A.W and Owojuyigbe O.S., Physicochemical properties of palm oil from different palm oil local factories in Nigeria.Journal of Food, Agriculture \& Environment. 2010; 8 (3\&4) ; 264-269.

[14] Morrison, W.H., R.J. Hamilton and C. Kalu. Sunflower seed oil. In; R.J.Hamilton,(ed.) Developments in oils and fats. Blackie Academic and Professional, Glasgow. 1995; 132-152.

[15] Moreira, R.G.; Castell-Perez, M.E.; Barrufet, M.A. Deep-Fat Frying Fundamentals and Applications; Aspen Publication: Gaithersburg, MD, 1999; 350 pp.

[16] Giese, J. Fats, Oils and Fat Replacers. Food Tech. 1996; 50; 78-84.

[17] Maskan, M.; Bagci, H.I. The Recovery of Used Sunflower Seed Oil Utilized in Repeated Deepfat Frying Process. Eur. Food Res. Tech. 2003; 218 ; 26-31.

[18] Yoshida, H., Y. Hirakawa, and S.Abe Influence of microwave roasting on positional distribution of fatty acids of triacylglycerols and phospholipids in sunflower seeds (Helianthus annuus L.) Eur., J. Lipid Sci. Technol.2002; 103: 201207.

[19] Megahed, M.G. Microwave roasting of peanuts: Effects on oil characteristics and composition Nahrung, 2001; 45: 225-257.

[20] Anjum, F., F.Anwar, A.Jamil and M.Iqbal Microwave roasting effects on the physico-chemical composition and oxdative stability of sunflower seed oil, J.Am Oil Chem.Soc.2006; 83; 777-784.

[21] Lee, Y. C., I.H. Kim, J. Change, Y.K. Rhee, H.I. Oh, and H.K. Park Chemical composition and oxidative stability of safflower oil prepared with expeller from safflower seeds roasted at different tempratures, J. Food Sci.2004; 69: 33-38.

[22] Farag, R.S. Influence of microwave and conventional heating on the quality of lipids in model and food systems. Fat Science Technology, 1994; 6, 215-222.

[23] Adams, MR and Moss, MO. Food Microbiology. 3rd Edition, Royal Society for Chemistry. 1999; 202-304.

[24] Cheesbrough, M. District Laboratory Practice in Tropical Countries part 2 Cambridge. Cambridge University Press. 2000; Pp 290-320. 
Military Technical College

Kobry El-Kobbah, Cairo, Egypt

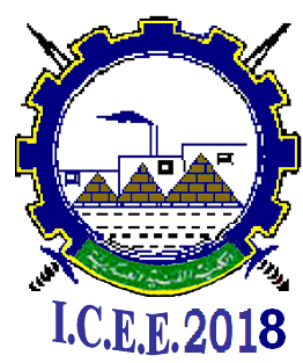

[25] Ehiri JE; Azubike MC; Ubbaonu, CN; Anyanwu, EC; Ibe, KM and Ogbonna, M. O. Bulletin of World Health Organization. 2001; 79(5); 423- 433.

[26] Ekwenye, UN and Ijeomah, C. A. KMITL Science Journal. 2005; 5(2); 502-505.

[27] Dellis. Mycology online. The University of Adelaide, Australia. 2006.

[28] Nwanekezi, EC and Oyeagba, RA. Journal of Food Agriculture and Environment, 2007; 5:956.

[29] Morgan DA. Smoke, fire, and flash points of cottonseed, peanut, and other vegetable oils. Oil \& Soap 1942; 19: 193.

[30] Wolke, Robert L. (May 16, 2007). "Where There's Smoke, There's a Fryer". The Washington Post. Retrieved March 5, 2011.

[31] Bockisch, Michael. Fats and Oils Handbook. Champaign, IL: AOCS Press.1998; pp. 95-96.

[32] Prosetyah H., Datta . (1991): Batch microwave heating of liquids; an experimental study. Journal of Microwave Power and Electromagnetic Energy, 26: 215-226.

[33] Susheelammn, N.S. Asha, M.R. Ravi, R. and Vasanth Kasanth. Department of Sensory Science, Central Food Technological Research Institute, Mysore - 570013, India, July 9, 2002.

[34] Rao, M.A. Rheology of Fluid and Semifluid Foods: Principles and Applications, Aspen Publication: Gaithersburg, MD, 1999; 433 pp.

[35] Noureddini, H.; Teoh, B.C.; Clements, D.L. Viscosities of Vegetable Oils and Fatty Acids. J. Am. Oil. Chem. Soc. 1999;69;1189-1191.

[36] Miller, K.S.; Singh, R.P.; Farkas, B.E. Viscosity and Heat Transfer Coefficients for Canola, Corn, Palm and Soybean Oil. J. Food Process. Preserv. 1994, 18, 461-472.

[37] Pak. J. Nutr. P.B. Ayoola and A. Adeyeye Department of Science Laboratory Technology, Ogbomoso, PMB. 4000, Ogbomoso, Oyo State, Nigeria , 2010; 9 (8) ; 751-754.

[38] ChristieWW. Triacylglycerols - structure, composition and analysis. The Lipid Library. Available at http://www.lipidlibrary.co.uk Access, 2004.

[39] Sekretar S., Schmidt S., Niklova I., Kovac M. Degradation effects of microwave heating on fats. Czech Journal of Food Sciences, 2000; 18 (Special Issue); 127128. 
Military Technical College

Kobry El-Kobbah,

Cairo, Egypt

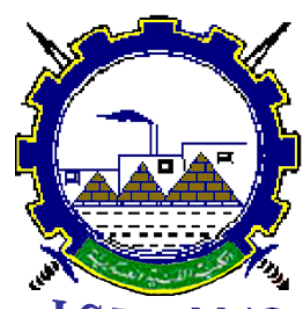

I.C.E.E.2018 $9^{\text {th }}$ International Conference

on

Chemical \& Environmental

Engineering

3-5 April 2018

Table1. Refractive index for both normal heating and microwave heating.

\begin{tabular}{|c|c|c|c|c|c|c|}
\hline \multirow{2}{*}{ Type of heating } & \multirow{2}{*}{$\begin{array}{l}\text { Exposure } \\
\text { time (min) }\end{array}$} & \multicolumn{5}{|c|}{ Refractive Index } \\
\hline & & Sunflower & Olive & Corn & Cotton & Supply \\
\hline \multirow{5}{*}{ Normal heating } & Zero & 1.461 & 1.468 & 1.465 & 1.46 & 1.4745 \\
\hline & 25 & 1.463 & 1.47 & 1.467 & 1.464 & 1.4749 \\
\hline & 50 & 1.468 & 1.471 & 1.469 & 1.467 & 1.476 \\
\hline & 75 & 1.47 & 1.472 & 1.47 & 1.468 & 1.4765 \\
\hline & 100 & 1.472 & 1.473 & 1.471 & 1.47 & 1.4776 \\
\hline \multirow{5}{*}{$\begin{array}{l}\text { Microwave } \\
\text { heating }\end{array}$} & Zero & 1.461 & 1.468 & 1.465 & 1.46 & 1.4745 \\
\hline & 20 & 1.462 & 1.469 & 1.466 & 1.462 & 1.475 \\
\hline & 40 & 1.464 & 1.47 & 1.468 & 1.465 & 1.4753 \\
\hline & 60 & 1.465 & 1.47 & 1.469 & 1.467 & 1.4765 \\
\hline & 80 & 1.466 & 1.471 & 1.47 & 1.467 & 1.477 \\
\hline
\end{tabular}

Table2. Percentage changes in refractive index of edible oils after heating four times, using normal heating and microwave exposure.

\begin{tabular}{|l|l|l|l|l|l|l|}
\hline \multirow{2}{*}{$\begin{array}{l}\text { Type } \\
\text { heating }\end{array}$} & $\begin{array}{l}\text { Exposure } \\
\text { time } \\
(\mathrm{min})\end{array}$ & \multicolumn{6}{|l|}{ Percentage change of Refractive Index } \\
\cline { 2 - 7 } & Zero & 0 & 0 & 0 & 0 & 0 \\
\hline \multirow{4}{*}{$\begin{array}{l}\text { Normal } \\
\text { heating }\end{array}$} & 25 & 0.136893 & 0.13624 & 0.136519 & 0.273973 & 0.027128 \\
\cline { 2 - 8 } & 50 & 0.479124 & 0.20436 & 0.273038 & 0.479452 & 0.101729 \\
\cline { 2 - 8 } & 75 & 0.616016 & 0.27248 & 0.341297 & 0.547945 & 0.135639 \\
\cline { 2 - 8 } & 100 & 0.752909 & 0.340599 & 0.409556 & 0.684932 & 0.210241 \\
\hline \multirow{4}{*}{$\begin{array}{l}\text { Microwave } \\
\text { heating }\end{array}$} & Zero & 0 & 0 & 0 & 0 & 0 \\
\cline { 2 - 8 } & 20 & 0.068446 & 0.06812 & 0.068259 & 0.136986 & 0.03391 \\
\cline { 2 - 8 } & 40 & 0.205339 & 0.13624 & 0.204778 & 0.342466 & 0.054256 \\
\cline { 2 - 8 } & 60 & 0.273785 & 0.13624 & 0.273038 & 0.479452 & 0.135639 \\
\hline \multirow{2}{*}{} & 80 & 0.342231 & 0.20436 & 0.341297 & 0.479452 & 0.169549 \\
\hline
\end{tabular}


Military Technical College

Kobry El-Kobbah,

Cairo, Egypt

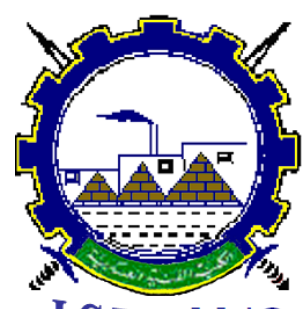

I.C.E.E.2018 $9^{\text {th }}$ International Conference

on

Chemical \& Environmental

Engineering

3-5 April 2018

Table3. Percentage changes in viscosity of edible oils after heating four times, using normal heating and microwave exposure.

\begin{tabular}{|c|c|c|c|c|c|c|}
\hline \multirow{2}{*}{$\begin{array}{l}\text { Type of } \\
\text { heating }\end{array}$} & \multirow{2}{*}{$\begin{array}{l}\text { Exposure } \\
\text { time (min) }\end{array}$} & \multicolumn{5}{|c|}{ Percentage change of Viscosity } \\
\hline & & Sunflower & Olive & Corn & Cotton & Supply \\
\hline \multirow{5}{*}{$\begin{array}{l}\text { Normal } \\
\text { heating }\end{array}$} & Zero & 0 & 0 & 0 & 0 & 0 \\
\hline & 25 & 8.108108 & 9.047619 & 12.8972 & 16.23377 & 19.56522 \\
\hline & 50 & 21.08108 & 12.69841 & 27.47664 & 30.73593 & 37 \\
\hline & 75 & 38.1982 & 20.95238 & 43.36449 & 47.61905 & 53.04348 \\
\hline & 100 & 53.15315 & 27.46032 & 53.83178 & 61.03896 & 66.95652 \\
\hline \multirow{5}{*}{$\begin{array}{l}\text { Microwave } \\
\text { heating }\end{array}$} & Zero & 0 & 0 & 0 & 0 & 0 \\
\hline & 20 & 1.261261 & 2.380952 & 6.728972 & 11.68831 & 15.65217 \\
\hline & 40 & 5.945946 & 4.603175 & 16.4486 & 19.91342 & 22.82609 \\
\hline & 60 & 9.90991 & 4.920635 & 22.42991 & 31.60173 & 33.26087 \\
\hline & 80 & 12.25225 & 6.349206 & 25.98131 & 43.29004 & 48.04348 \\
\hline
\end{tabular}

Table4. Flash temperature for normal heating.

\begin{tabular}{|c|c|c|c|c|c|c|}
\hline \multirow{2}{*}{$\begin{array}{l}\text { Type of } \\
\text { heating }\end{array}$} & \multirow{2}{*}{$\begin{array}{l}\text { Exposure } \\
\text { time (min) }\end{array}$} & \multicolumn{5}{|c|}{ Flash temperature } \\
\hline & & Sunflower & Olive & Corn & Cotton & Supply \\
\hline \multirow{5}{*}{$\begin{array}{l}\text { Normal } \\
\text { heating }\end{array}$} & Zero & 0 & 0 & 0 & 0 & 0 \\
\hline & 25 & 280 & 245 & 310 & 260 & 233 \\
\hline & 50 & 230 & 230 & 245 & 235 & 205 \\
\hline & 75 & 200 & 210 & 220 & 210 & 190 \\
\hline & 100 & 180 & 190 & 200 & 180 & 185 \\
\hline
\end{tabular}


Military Technical College

Kobry El-Kobbah,

Cairo, Egypt

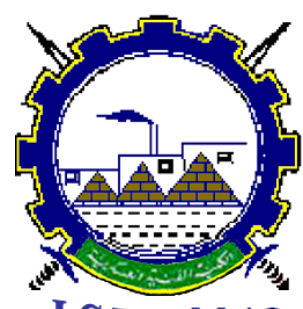

I.C.E.E.2018 $9^{\text {th }}$ International Conference

on

Chemical \& Environmental

Engineering

3-5 April 2018

Table5. Percentage changes in flash temperature of edible oils after heating four times, using normal heating.

\begin{tabular}{|l|l|l|l|l|l|l|}
\hline \multirow{3}{*}{$\begin{array}{l}\text { Type of } \\
\text { heating }\end{array}$} & \multirow{6}{*}{$\begin{array}{l}\text { Exposure } \\
\text { time (min) }\end{array}$} & \multicolumn{5}{l|}{ Percentage change of Flash temperature } \\
\cline { 3 - 7 } & & Sunflower & Olive & Corn & Cotton & Supply \\
\hline \multirow{4}{*}{$\begin{array}{l}\text { Normal } \\
\text { heating }\end{array}$} & Zero & 0 & 0 & 0 & 0 & 0 \\
\cline { 2 - 8 } & 25 & 0 & 0 & 0 & 0 & 0 \\
\cline { 2 - 8 } & 50 & 17.85714 & 6.122449 & 20.96774 & 9.615385 & 12.01717 \\
\cline { 2 - 8 } & 100 & 28.57143 & 14.28571 & 29.03226 & 19.23077 & 18.45494 \\
\hline
\end{tabular}

Table6. Percentage changes in saponification number of edible oils after heating four times, using normal and microwave heating.

\begin{tabular}{||l|l|l|l|l|l|l||}
\hline \multirow{2}{*}{$\begin{array}{l}\text { Type } \\
\text { heating }\end{array}$} & $\begin{array}{l}\text { Exposure } \\
\text { time }(\mathrm{min})\end{array}$ & \multicolumn{5}{|l|}{ Percentage change of Saponification Number } \\
\hline \multirow{4}{*}{$\begin{array}{l}\text { Normal } \\
\text { heating }\end{array}$} & Zero & 0 & 0 & 0 & 0 & 0 \\
\cline { 2 - 8 } & 25 & 20 & 40 & 23.80952 & 4.545455 & 7.692308 \\
\cline { 2 - 8 } & 50 & 72 & 40 & 33.33333 & 22.72727 & 73.07692 \\
\cline { 2 - 8 } & 75 & 88 & 45 & 47.61905 & 50 & 88.46154 \\
\cline { 2 - 8 } & 100 & 100 & 55 & 57.14286 & 86.36364 & 96.15385 \\
\hline \multirow{4}{*}{$\begin{array}{l}\text { Microwave } \\
\text { heating }\end{array}$} & Zero & 0 & 0 & 0 & 0 & 0 \\
\cline { 2 - 8 } & 20 & 8 & 15 & 14.28571 & 4.545455 & 3.846154 \\
\cline { 2 - 8 } & 40 & 12 & 20 & 23.80952 & 9.090909 & 7.692308 \\
\cline { 2 - 8 } & 60 & 20 & 30 & 33.33333 & 22.72727 & 19.23077 \\
\cline { 2 - 8 } & 80 & 28 & 35 & 38.09524 & 36.36364 & 26.92308 \\
\hline
\end{tabular}




\begin{tabular}{|c|c|}
\hline Proceeding of the $9^{\text {th }}$ ICEE Conference 3-5 April 2018 & NBC \\
Military Technical College \\
Kobry El-Kobbah, \\
Cairo, Egypt
\end{tabular}

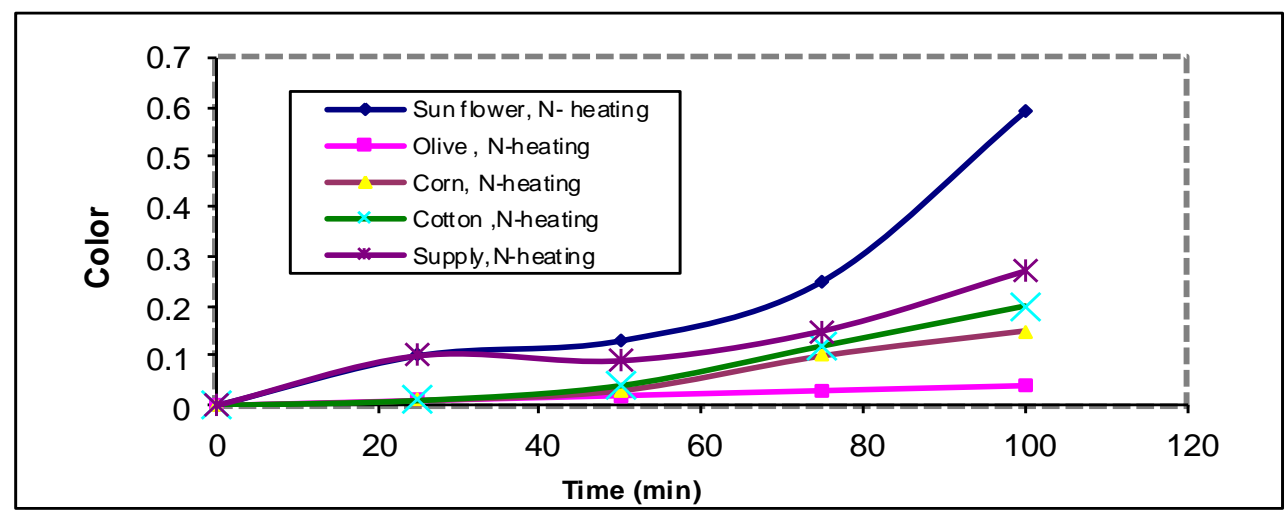

Fig.1. Change in color intensity using normal heating.

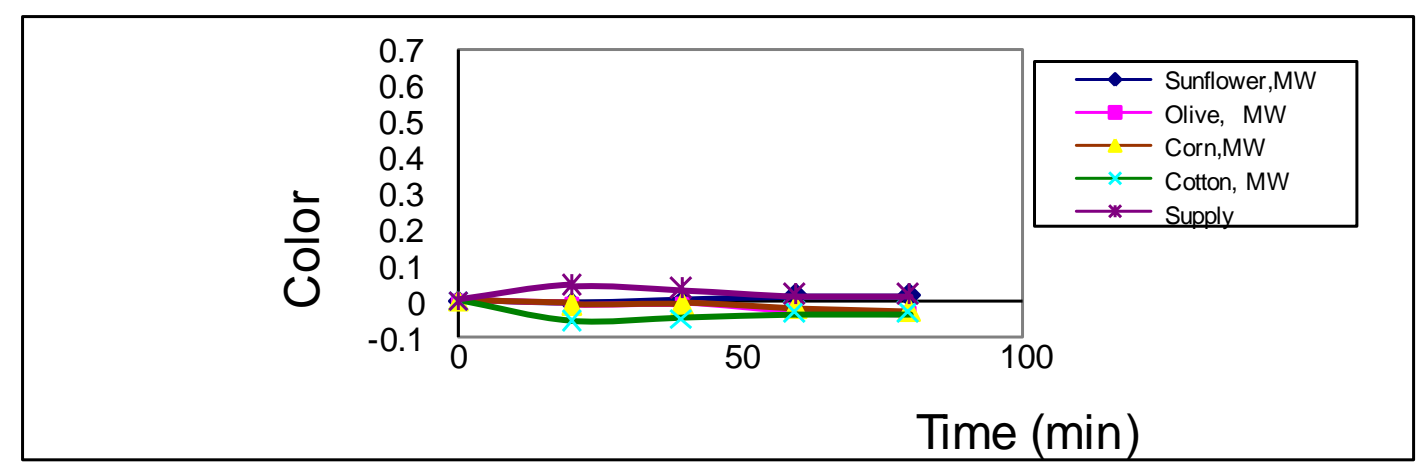

Fig.2. Change in color intensity using microwave heating.

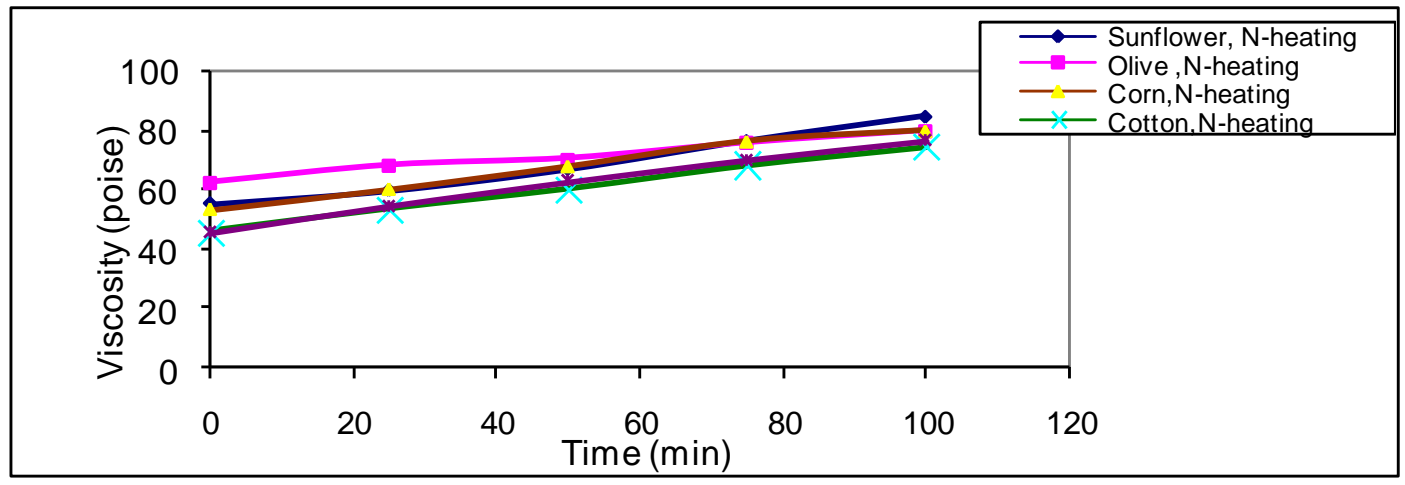

Fig.3. Change in viscosity using normal heating. 


\begin{tabular}{|c|c|}
\hline Proceeding of the $9^{\text {th }}$ ICEE Conference 3-5 April 2018 & NBC \\
Military Technical College \\
Kobry El-Kobbah, \\
Cairo, Egypt
\end{tabular}

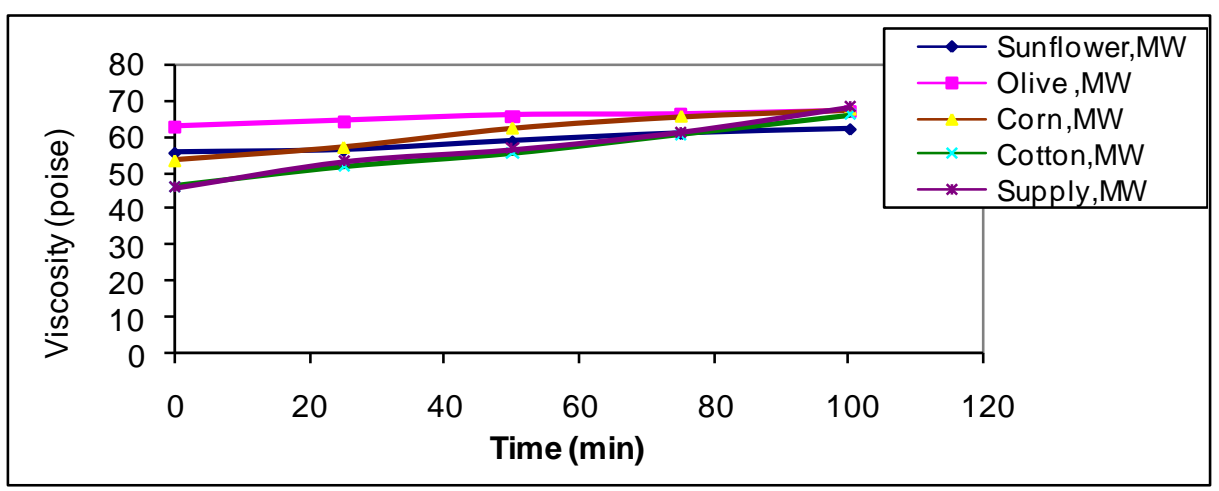

Fig.4. Change in viscosity using microwave heating.

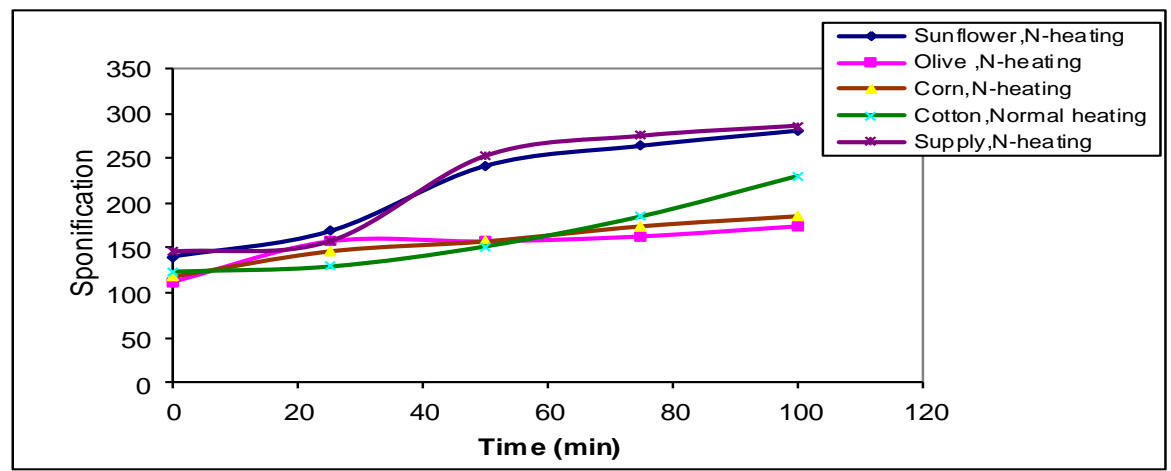

Fig.5. Change in saponification number with normal heating

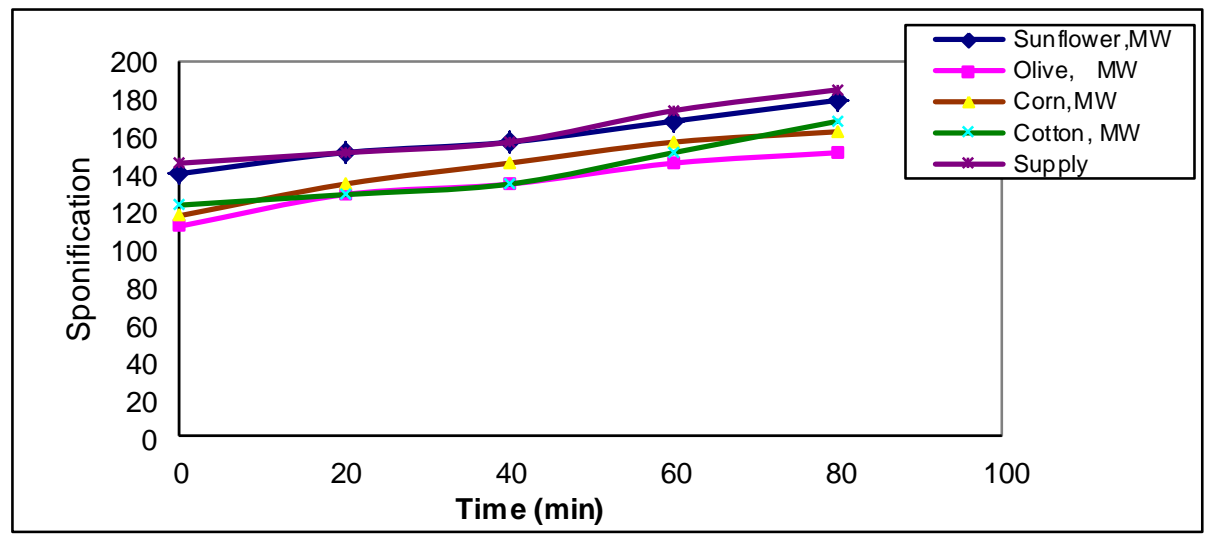

Fig.6. Change in saponification number of with microwave heating. 


\begin{tabular}{|c|c|}
\hline Proceeding of the $9^{\text {th }}$ ICEE Conference 3-5 April 2018 & NBC \\
Military Technical College \\
Kobry El-Kobbah, \\
Cairo, Egypt
\end{tabular}

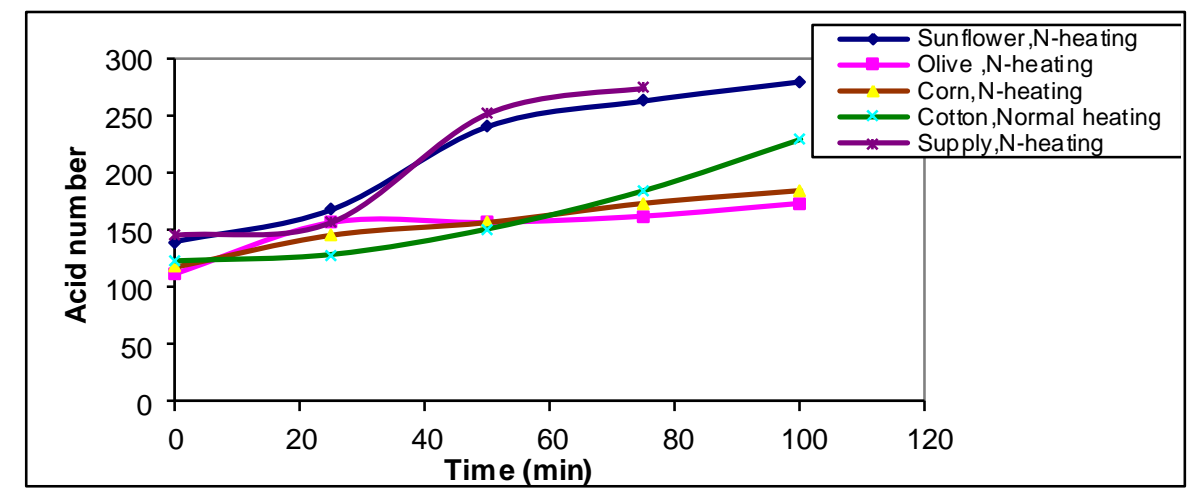

Fig.7. Change in acid value with normal heating.

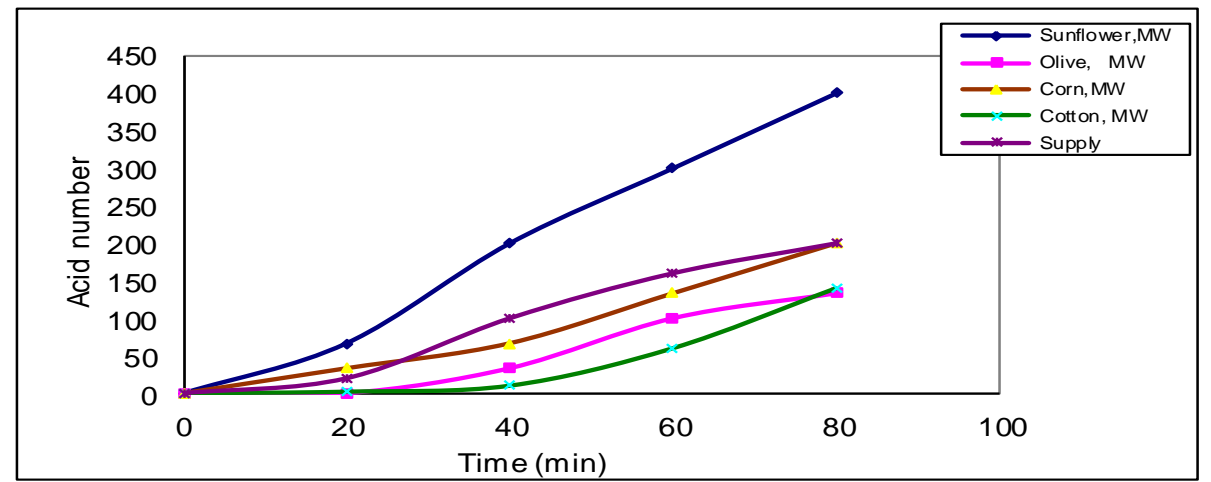

Fig. 8. Change in acid value with microwave heating.

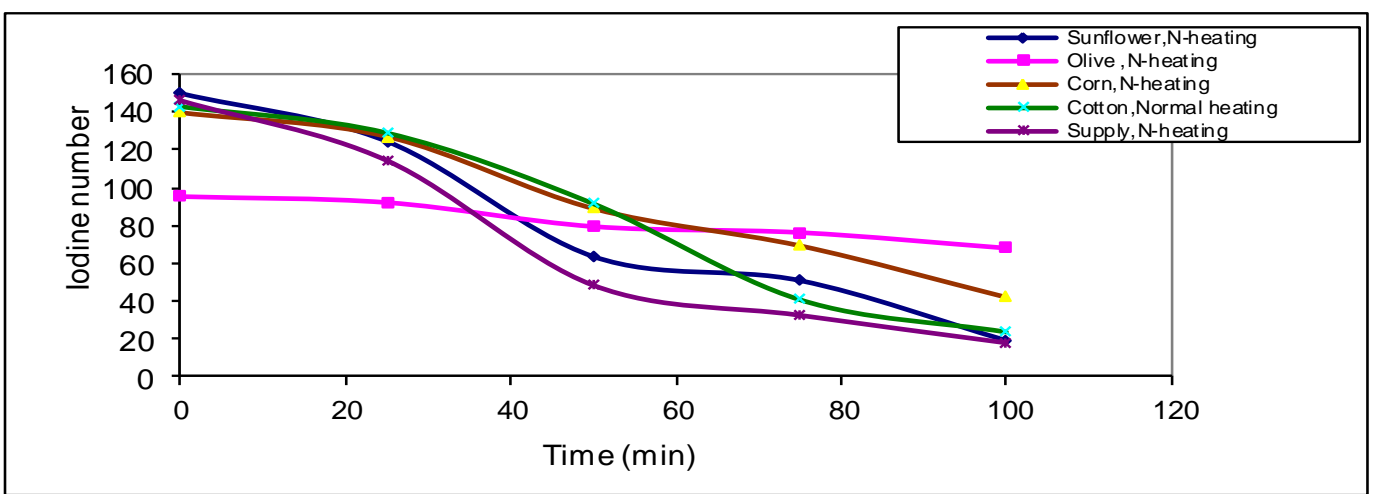

Fig. 9 Change in iodine number of with microwave normal heating. 


\begin{tabular}{|c|c|}
\hline Proceeding of the $9^{\text {th }}$ ICEE Conference 3-5 April 2018 & NBC \\
Military Technical College \\
Kobry El-Kobbah, \\
Cairo, Egypt
\end{tabular}

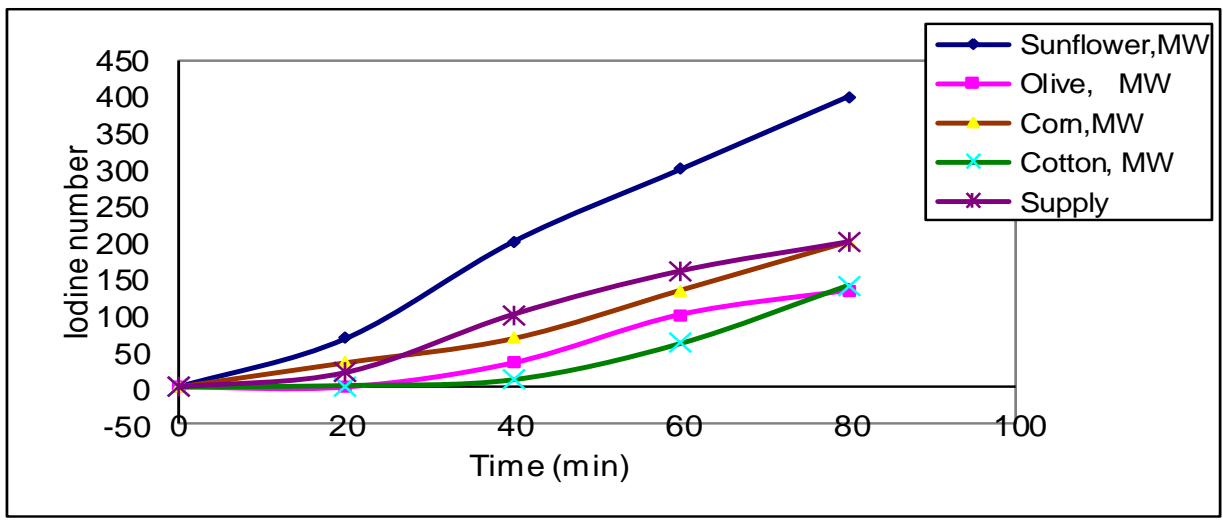

Fig. 10. Change in iodine number with microwave heating.

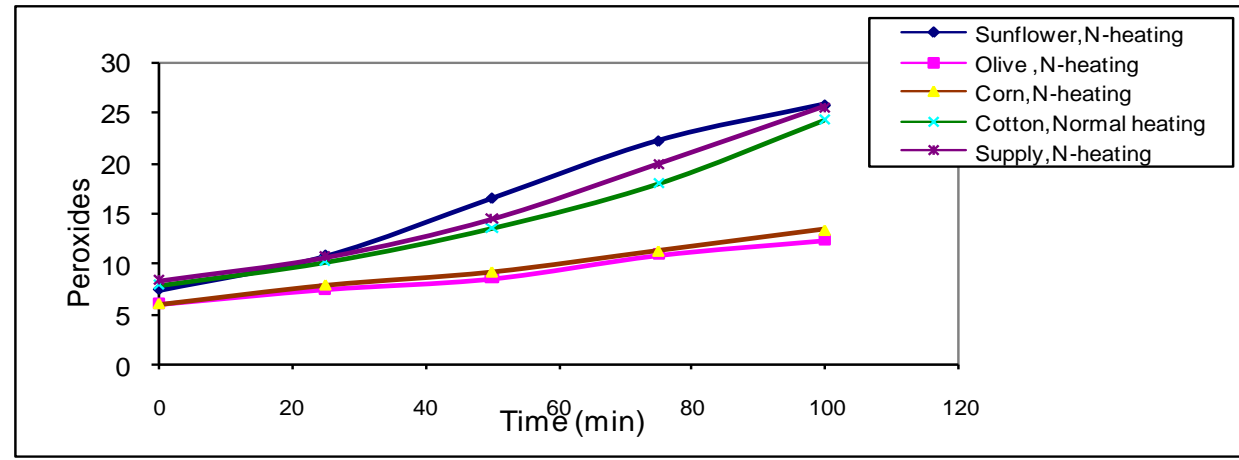

Fig.11. Change in peroxides value with normal heating.

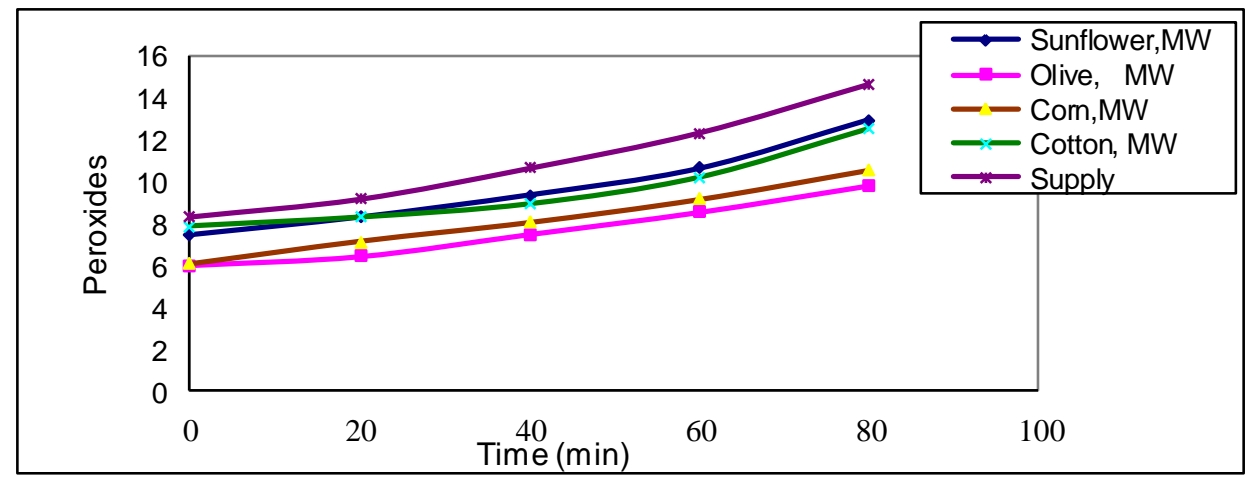

Fig. 12. Change in peroxide value with microwave heating. 